\title{
Bioestimulantes em sementes de olerícolas submetidos a testes de germinação e vigor
}

Biostimulants in vegetable seeds submitted to germination and vigor tests

\author{
I. S. Romagna; E. Junges*; P. A. Karsburg; S. Q. Pinto \\ Instituto Federal Farroupilha, 97420-000, São Vicente do Sul- Rio Grande do Sul, Brasil
}

*izabelleromagna@gmail.com

(Recebido em 14 de março de 2019; aceito em 15 de outubro de 2019)

\begin{abstract}
A utilização de bioprodutos, economicamente viáveis, são de extrema importância na proteção e estimulo de germinação em culturas olerícolas. Este trabalho avaliou o efeito dos microrganismos Azospirillum brasiliense, Bacillus subtilis, Trichoderma harzianum e o produto comercial para tratamento de sementes (Fipronil + Pilaclostrobina e Metil Tiofanato) em sementes e plântulas de alface (Lactuca sativa), cenoura (Daucus carota) e tomate (Solanum lycopersicum). As sementes foram inoculadas antes de serem submetidas à teste de germinação. O tratamento químico mostrou-se ineficiente na proteção da semente de todas as culturas e estimulo de germinação. A T. harzianum aumentou o índice germinativo de sementes de alface, teve melhores valores em tamanho de sistema radicular na cultura do tomate e estimulou a emissão de radícula na cenoura. O B. subtilis destacou-se no acúmulo de matéria seca na cultura do tomate. Os microrganismos B. subtilis e T. harzianum apresentam potencial para tratamento de sementes de hortaliças. Palavras-chave: bioprodutos, tratamento de sementes, hortaliças.
\end{abstract}

The use of economically viable bioproducts are extremely important in the protection and stimulation of germination in olive groves. This work evaluated the effect of Azospirillum brasiliense, Bacillus subtilis, Trichoderma harzianum and the commercial seed treatment product (Fipronil + Pilaclostrobin and Methyl Thiophanate) on seeds and seedlings of lettuce (Lactuca sativa), carrot (Daucus carota) and tomato (Solanum lycopersicum). The seeds were inoculated before being submitted to the germination test. The chemical treatment proved to be inefficient in protecting the seed of all crops and stimulating germination. $T$. harzianum increased the germination index of lettuce seeds, had better values in root system size in the tomato crop and stimulated the emission of radicle in the carrot. B. subtilis was noted in the accumulation of dry matter in the tomato crop. The microorganism's B. subtilis and T. harzianum present potential for the treatment of vegetable seeds.

Keywords: bioproducts, seeds tratament, vegetables.

\section{INTRODUÇÃO}

A olericultura é um ramo da agricultura que se dedica a produção de culturas folhosas, raízes, bulbos, tubérculos e diversas partes comestíveis, utilizadas na dieta humana, sem necessariamente, exigir industrialização. Na alimentação constitui um importante papel no fornecimento de micronutrientes, fibras e outros elementos essenciais para a saúde [1].

A maior peculiaridade deste ramo é sua grande variabilidade de produtos e atividades realizadas durante as quatro estações do ano. Além disso, a concentração de produção ocorre em propriedades de agricultura familiar, intensivamente utilizadas em espaço e tempo, fato que não impede sua expressiva atuação na economia do país. Segundo a Confederação da Agricultura e Pecuária do Brasil (CNA), em 2016, o cultivo de hortaliças ocupou uma área de aproximadamente 837 mil hectares, com volume de produção de 63 milhões de toneladas, contemplando mais de uma centena de espécies cultivadas em todo território brasileiro. A busca por alimentos mais saudáveis, práticos de consumir e ricos nutritivamente é uma tendência que os consumidores estão seguindo. Segundo Ceratti (2018) [2], mercado de alimentos saudáveis, no Brasil, atingiu R \$93,6 bilhões em vendas, com uma previsão de crescimento anual de 4,4\% até o ano de 2021 .

Dentro da cadeia produtiva de hortaliças, a produção de mudas caracteriza-se por uma atividade altamente tecnificada, que exige conhecimento da cultura em questão. O sucesso para a produção de mudas está vinculado a diversos aspectos, começando pelo estabelecimento de 
plântulas, o qual está diretamente ligado à qualidade de sementes [3]. Portanto, a utilização de sementes de alta qualidade diminui riscos relacionados ao estabelecimento de plântulas, etapa do processo produtivo de grande importância para espécies olerícolas devido ao alto custo para a aquisição desse insumo [3].

Das espécies propagadas por sementes, a cenoura (Daucus carota), tomate (Solanum lycopersicum) e a alface (Lactuca sativa), possuem uma grande aceitação no mercado devido suas características nutritivas. A parte comercializada e consumida da cenoura é sua raiz, rica em betacaroteno e fibras, devido seu florescimento ser caracterizado por um amplo período, as sementes ficam expostas a desuniformidades e diferenciação em qualidade fisiológica [4]. Encontra-se entre as dez espécies de hortaliças mais cultivadas no Brasil [4]. O tomate possui fins diversificados como in natura, processado como suco, pasta, molho ou vendido seco para consumo [5]. Um problema encontrado na produção de sementes de tomate é aliar a utilização de espécies adaptadas com a produção de sementes de alta qualidade, para atribuir à produção sementes com rápida germinação produzindo plantas vigorosas e sadias [6]. A alface, destaca-se por ser a folhosa mais importante na alimentação dos brasileiros [7]. Os fatores que mais interferem na germinação e propagação da cultura são umidade e temperatura que regula diretamente a germinação e indiretamente a dormência e viabilidade de sementes [8].

Diversos microrganismos são estudados como bioestimulantes de crescimento e proteção das plantas. De acordo com Vieira e Castro (2001) [8] a mistura de dois ou mais reguladores de crescimento ou de reguladores com outras substâncias, é denominado bioestimulante. Os aminoácidos e hidrolisados de proteínas, substâncias húmicas, extratos de algas e os microrganismos são grupos que vem adquirindo importância em estudos relacionando seu uso em tratamento de sementes. Os microrganismos bioestimulantes podem atuarem como promotores de crescimento através da produção dos principais hormônios de crescimento da planta [10].

Azospirillum spp. é conhecido por ser uma rizobactéria promotora de crescimento [11]. Estes microrganismos são encontrados, principalmente, em rizosferas de monocotiledôneas, entretanto, já existe informações em dicotiledôneas [12]. Situa-se entre os principais grupos estudados por possuir mecanismos como produção de fitormônios, fornecimento de pequenas moléculas de enzimas, ampliação do sistema radicular, melhoria na atividade da membrana e reduzir a intensidade de estresses climáticos [13]. Hungria et al. (2011) [13] destacam a capacidade do gênero em ampliar o sistema radicular de diversas plantas, por meio da produção de fitormônios, possibilitando à planta uma maior área para absorção de água e nutrientes.

A bactéria Bacillus subtilis tem a capacidade de sobreviver em ambientes hostis, promover o crescimento ou proteção de plantas através da produção de compostos e ação de redução de doenças [15]. Trata-se de microrganismos cosmopolitas, habitantes naturais do solo, comumente encontrados associados à rizosfera de plantas [16]. Braga Junior (2015) [16] verificou a capacidade de Bacillus subtilis promover crescimento em feijão caupi, produzindo valores superiores de biomassa. De Araújo e Marchesi (2009) [17] observaram a capacidade do B. subtilis em aumentar a biomassa da parte aérea do tomateiro, além de reduzir em $50 \%$ a reprodução de nematoides do gênero Meloidogyne spp.

Trichoderma harzianum é encontrado, naturalmente, em quase todos os tipos de solo. É bastante conhecido como agente de biocontrole de fungos fitopatogênicos e no tratamento de sementes oferecendo às raízes das plântulas vantagem competitiva [19]. Diante do atual cenário justifica-se o uso de produtos que protejam as sementes ou que estimulem seu desenvolvimento inicial. Portanto, o objetivo deste trabalho foi avaliar a ação dos microrganismos bioestimulantes Azospirillum brasiliense, Bacillus subtilis, Trichoderma harzianum na germinação e vigor de sementes de cenoura, tomate e alface.

\section{MATERIAL E MÉTODOS}

Foram utilizadas sementes sem qualquer tratamento químico das culturas: cenoura (Daucus carota) cultivar Brasília, tomate (Solanum lycopersicum) tipo Santa Clara e a alface (Lactuca sativa) lisa, ambas da empresa TSV Sementes®. Nestas sementes foram aplicados os seguintes produtos: Testemunha (composto apenas de água destilada e esterelizada), Azospirillum 
brasiliense (SimbioseMaíz $\left.{ }^{\circledR}\right)$, Bacillus subtilis (Bactel $\left.{ }^{\circledR}\right)$, Trichoderma harzianum (Trichodel ${ }^{\circledR}$ ) e produto comercial para tratamento de sementes STANDAK® TOP (Fipronil + Pilaclostrobina e Metil Tiofanato). As sementes foram inoculadas com os tratamentos em uma dose de $2 \%$ do peso da amostra, homogeneizado suavemente em sacos plásticos e, em seguida, submetidas aos testes de germinação e vigor.

O teste de germinação foi conduzido em caixas gerbox desinfestadas e cada tratamento continha 100 sementes divididas em quatro repetições com 25 sementes. Os testes foram instalados segundo as recomendações das Regras de Análise de Sementes (RAS). Posteriormente, as caixas gerbox foram armazenadas em sacos plásticos para evitar a perda de umidade e alocadas em uma sala de crescimento, com temperatura de $25^{\circ} \mathrm{C}$ e fotoperíodo de 12 horas. A primeira e última contagem foram realizadas aos sete e quatorze dias para cenoura, cinco e quatorze dias para tomate e quatro e sete dias para a alface. O método para a determinação do vigor utilizado foi a primeira contagem de germinação [20].

As variáveis avaliadas foram: emissão de radícula (\%): determinada na primeira contagem do teste de germinação de cada cultura e expresso em percentual de sementes que apresentavam radícula; germinação (\%): \% plântulas normais na primeira e segunda contagem do teste seguindo as Regras de Análise de Sementes (RAS). Destas plântulas foi determinado o comprimento da parte aérea $(\mathrm{cm})$, comprimento sistema radicular $(\mathrm{cm})$ utilizando régua milimetrada e a massa seca de plântulas (mg) determinada após secagem em estufa com ventilação de ar forçada à $65^{\circ} \mathrm{C}$ durante 24 horas e pesadas em balança de precisão [20].

$\mathrm{O}$ trabalho foi conduzido em delineamento experimental, inteiramente ao acaso, e os tratamentos foram arranjados em esquema fatorial 3 x 5, sendo o fator A três cultura diferentes (cenoura, alface e tomate) e o fator B diferentes tratamentos de sementes (testemunha, $A$. brasiliense, B. subtilis, T. harzianum e produto comercial). Após as avaliações, os dados foram submetidos à análise estatística pelo teste de Scott-Knott a 5\% de significância, utilizando o programa SISVAR versão 5.6 [21].

\section{RESULTADOS E DISCUSSÃO}

A análise estatística demonstrou haver interação entre os fatores, o que demonstra respostas diferentes dos tratamentos de sementes utilizados para cada cultura testada.

$\mathrm{Na}$ cultura da cenoura, alguns parâmetros, germinação, emissão de radícula, tamanho de parte aérea e acúmulo de matéria seca das plântulas, não foram afetados pelos produtos utilizados no tratamento das sementes (Tabela 1). O tratamento com $T$. harzianum favoreceu o crescimento do sistema radicular das plântulas de cenoura, superando os outros bioestimulantes testados. $\mathrm{O}$ valor comercial da cultura em questão é sua raiz, portanto, estabelecimento de plântulas com sistema radicular bem desenvolvido tem a tendência de formar plantas com a raiz mais vigorosa, consequentemente, elevando a produtividade. Trichoderma spp. possui grande versatilidade de ação, como parasitismo, antibiose e competição [22]. A ação como estimulador de crescimento, é complexa, realizada por interações como fatores bioquímicos e produção de várias enzimas e compostos benéficos [23]. Pedroso et al. (2014) [23] testaram o efeito de T. harzianum em sementes de cenoura infestadas com Alternaria alternata encontrando valores superiores de germinação em relação à testemunha.

$\mathrm{O}$ tratamento com A. brasiliense e com B. subtilis também favoreceram o crescimento do sistema radicular de cenoura, porém com menor expressão. Em seu trabalho, Dognini (2017) [24] encontrou resultados que discordam com os resultados obtidos no presente trabalho, ao tratar sementes de cenoura com $B$. subtilis, o tratamento com o microrganismo, reduziu o sistema radicular das plântulas de $3,46 \mathrm{~cm}$, tratamento controle, para $3,10 \mathrm{~cm}$ tratamento com B.subtilis. O Azospirillum spp. é especialmente conhecido como fixador de nitrogênio, entretanto, pesquisas apontam seu potencial na síntese de fitormônios e outros compostos que agem diretamente na planta em forma de respostas benéficas em seu crescimento [26]. O tratamento químico teve os piores valores em todas as variáveis, não produzindo benefícios e retardando a germinação de sementes de cenoura. 
Como pode ser observado, o tratamento químico prejudicou os parâmetros fisiológicos avaliados em todas as culturas (cenoura, tomate e alface), reduzindo o percentual germinativo. $\mathrm{O}$ produto químico foi incluso nos tratamentos para fins de teste, buscando-se obter uma comparação entre produtos biológicos e químicos. Entretanto, o produto não é registrado para hortaliças, o que pode justificar seu efeito nas características fisiológicas, uma vez que não há padrão de doses recomendadas nem critérios para seu uso em espécies hortícolas [27].

Tabela 1: Percentual germinativo (GER), emissão de radícula (ERA), tamanho de parte aérea (TPA), tamanho de sistema radicular (TSR) e massa seca de plântulas (TMS) de cenoura (Daucus carota) submetido ao teste de germinação em laboratório, inoculado com Azospirillum brasiliense, Bacillus subtilis, Trichoderma harzianum, tratamento químico e testemunha.

\begin{tabular}{cccccc}
\hline TRAT & GER $(\boldsymbol{\%})$ & ERA $(\%)$ & TPA $(\mathbf{c m})$ & TSR $(\mathbf{c m})$ & TMS (mg) \\
\hline Testemunha & $87 \mathbf{A}$ & $85 \mathbf{A}$ & $4,7 \mathbf{A}$ & $1,15 \mathbf{~ C}$ & $9,92 \mathbf{A}$ \\
A. brasiliense & $86 \mathbf{A}$ & $83 \mathbf{A}$ & $4,68 \mathbf{A}$ & $1,66 \mathbf{~ B}$ & $11,17 \mathbf{A}$ \\
B. subtilis & $84 \mathbf{A}$ & $79 \mathbf{A}$ & $4,87 \mathbf{A}$ & $1,81 \mathbf{B}$ & $9,15 \mathbf{A}$ \\
T. harzianum & $83 \mathbf{A}$ & $73 \mathbf{A}$ & $4,93 \mathbf{A}$ & $2,22 \mathbf{A}$ & $9,85 \mathbf{A}$ \\
Químico & $28 \mathbf{~ B}$ & $40 \mathbf{~}$ & $1,14 \mathbf{~ B}$ & $0,84 \mathbf{C}$ & $9,22 \mathbf{A}$ \\
\hline CV (\%) & 11,78 & 12,42 & 7,40 & 15,17 & 50,15 \\
\hline
\end{tabular}

Médias seguidas por letras iguais não diferem entre si pelo teste Scott Knott a 5\% de probabilidade.

$\mathrm{Na}$ avaliação de bioestimulantes aplicados em sementes de tomate (Tabela 2), foi possível observar que a germinação não sofreu influência dos tratamentos utilizados. Esses resultados diferem dos encontrados por Ethur et al. (2008) [27], em que a germinação no tratamento controle teve diferença significativa em relação aos tratamentos que continham isolados de T. harzianum, apresentando menor percentual de germinação. $\mathrm{O}$ acúmulo de massa seca de plântulas de tomate foi responsivo ao tratamento com Bacillus subtilis, isso evidencia que as plântulas oriundas de sementes tratadas com esse microrganismo podem se tornar mais rústicas, e sobreviver a condições adversas do ambiente. As bactérias do gênero Bacilllus spp. são caracterizadas por produzirem compostos que estimulam o crescimento das plantas e melhoram as condições ao estresse, exibem uma interação significativa com as raízes das plantas, aprimorado pela indução de resistência sistêmica, antibiose, omissão competitiva e outros mecanismos [29]. Trichoderma harzianum aplicado às sementes de tomate reduziu o crescimento das plântulas produzidas, outros autores já observaram que em certas condições $T$. harzianum pode prejudicar o desempenho das plântulas. Junges et al. (2014) [29] observaram que utilizando técnicas de microbiolização que intensificaram a colonização de Trichoderma spp. em sementes de milho houve prejuízo à germinação e ao vigor desta cultura. A utilização de A. brasiliense não demonstrou influência sobre as variáveis analisadas. Cotrim et al. (2016) [30] demonstraram que a utilização de $A$. brasiliense não alterou a germinação de sementes de trigo, porém, a inoculação via semente conferiu maior resistência às plântulas quando as sementes foram expostas à condições adversas de temperatura e umidade. 
Tabela 2: Percentual germinativo (GER), emissão de radícula (ERA), tamanho de parte aérea (TPA), tamanho de sistema radicular (TSR) e massa seca de plântulas (TMS) de tomate (Solanum lycopersicum) submetido ao teste de germinação em laboratório, inoculado com Azospirillum brasiliense, Bacillus subtilis, Trichoderma harzianum, tratamento químico e testemunha.

\begin{tabular}{cccccc}
\hline TRAT & GER $(\%)$ & ERA $(\%)$ & TPA $(\mathbf{c m})$ & TSR $(\mathbf{c m})$ & TMS $(\mathbf{m g})$ \\
\hline Testemunha & $91 \mathbf{A}$ & $91 \mathbf{A}$ & $3,94 \mathbf{A}$ & $5,55 \mathbf{A}$ & $37,60 \mathbf{B}$ \\
A. brasiliense & $85 \mathbf{A}$ & $55 \mathbf{A}$ & $3,98 \mathbf{A}$ & $4,88 \mathbf{A}$ & $32,52 \mathbf{B}$ \\
B. subtilis & $95 \mathbf{A}$ & $31 \mathbf{~ B}$ & $3,53 \mathbf{~ B}$ & $1,26 \mathbf{B}$ & $46,17 \mathbf{A}$ \\
T. harzianum & $89 \mathbf{A}$ & $63 \mathbf{A}$ & $3,30 \mathbf{~ B}$ & $1,58 \mathbf{B}$ & $35,20 \mathbf{B}$ \\
Químico & $0 \mathbf{B}$ & $0 \mathbf{B}$ & $0,00 \mathbf{C}$ & $0,00 \mathbf{C}$ & $0,00 \mathbf{C}$ \\
\hline CV(\%) & 8,96 & 62,99 & 10,35 & 42,72 & 11,24 \\
\hline
\end{tabular}

Médias seguidas por letras iguais não diferem entre si pelo teste Scott Knott a 5\% de probabilidade.

Nas sementes de alface os tratamentos com T. harzianum e B. subtilis promoveram maior percentual de emissão de radícula, porém Trichoderma harzianum acarretou em plântula com tamanho de parte aérea e raiz inferior às sementes sem tratamento (Tabela 3). Quanto à germinação, a testemunha junto com o tratamento com $T$. harzianum apresentaram os melhores valores, diferindo-se significativamente dos demais tratamentos. Diniz et al. (2006) [31] encontraram resultados semelhantes de germinação, ao avaliar o efeito da Trichoderma sp. $(91,13 \%)$ em sementes de alface, não apresentando diferença significativa em relação à testemunha $(94,44 \%)$. A utilização de $B$. subtilis acelerou a emissão de radícula, porém isso não correspondeu a maior percentual de germinação. A. brasiliense não agiu como bioestimulante quando associado às sementes de alface, causando redução da germinação, do tamanho da parte aérea e acúmulo de matéria seca. $\mathrm{O}$ tratamento químico também prejudicou o desempenho das plântulas de alface, para todas as variáveis observadas.

Tabela 3: Percentual germinativo (GER), emissão de radícula (ER), tamanho de parte aérea (TPA), tamanho de sistema radicular (TSR) e massa seca de plântulas (TMS) da alface (Lactuca sativa) submetido ao teste de germinação em laboratório, inoculado com Azospirillum brasiliense, Bacillus subtilis, Trichoderma harzianum, tratamento químico e testemunha.

\begin{tabular}{|c|c|c|c|c|c|}
\hline TRAT & GER (\%) & ERA $(\%)$ & TPA $(\mathrm{cm})$ & TSR $(\mathbf{c m})$ & TMS (mg) \\
\hline Testemunha & $75 \mathrm{~A}$ & 64 B & $2,85 \mathbf{A}$ & $1,84 \mathbf{A}$ & $13,52 \mathrm{~A}$ \\
\hline A. brasiliense & $52 \mathrm{~B}$ & 72 B & $1,81 \mathbf{B}$ & $1,83 \mathbf{A}$ & $9,125 \mathbf{B}$ \\
\hline B. subtilis & $37 \mathbf{B}$ & $88 \mathrm{~A}$ & $2,85 \mathbf{A}$ & $2,07 \mathbf{A}$ & $12,12 \mathbf{A}$ \\
\hline T. harzianum & $78 \mathbf{A}$ & $85 \mathrm{~A}$ & $2,33 \mathbf{B}$ & $1,27 \mathbf{B}$ & $16,07 \mathbf{A}$ \\
\hline Químico & $28 \mathbf{B}$ & $15 \mathrm{C}$ & $0,36 \mathbf{C}$ & $0,65 \mathbf{B}$ & $4,12 \mathbf{C}$ \\
\hline $\mathrm{CV}(\%)$ & 43,47 & 12,90 & 13,28 & 39,34 & 26,53 \\
\hline
\end{tabular}

Médias seguidas por letras iguais não diferem entre si pelo teste Scott Knott a 5\% de probabilidade.

A comparação do efeito de diferentes microrganismos bioestimulantes em culturas hortícolas diferentes permitiu observar que as repostas são variáveis, havendo a necessidade de avaliar essas interações caso a caso, não sendo possível extrapolar que o melhor tratamento para uma cultura assim será as demais. Os microrganismos com maior potencial bioestimulante para as culturas da cenoura, tomate e alface, nas condições deste ensaio, foram Trichoderma harzianum e Bacillus subtilis. Ambos os microrganismos produziram melhor desempenho fisiológico das plântulas, o que pode promove benefícios iniciais e também ao longo do ciclo de cultivo. Diante da pouca disponibilidade de produtos químicos registrados para o tratamento de 
sementes de hortaliças [27], bem como a importância das culturas olerícolas para a alimentação humana [1] os benefícios observados com os tratamentos biológicos de sementes possibilitam melhorias na produção de mudas e podem repercutir em ganhos de produtividade e qualidade dos produtos. Mesmo não tendo sido observado efeito da utilização de Azospirillum brasiliense sobre as plântulas os benefícios da utilização deste bioestimulante poderão ocorrer nos momentos de maior demanda nutricional, quando a cultura estiver a campo [32].

\section{CONCLUSÃO}

Cenoura, tomate e alface respondem de maneira diferente ao tratamento de sementes com bioestimulantes. A cultura da cenoura demonstrou ser a mais beneficiada pela utilização de bioestimulantes aplicados às sementes.

Trichoderma harzianum estimula o crescimento do sistema radicular de plântulas de cenoura.

Ocorre incremento de massa seca de plântulas de tomate quando as sementes são tratadas com Bacillus subtilis.

Os microrganismos Trichoderma harzianum e Bacillus subtilis aumentam o percentual de emissão de radícula em sementes de alface.

\section{AGRADECIMENTOS}

Fundação de Amparo à Pesquisa do Estado do Rio Grande do Sul pela concessão de bolsa.

\section{REFERÊNCIAS BIBLIOGRÁFICAS}

1. De Melo PCT, Vilela NJ. Importância da cadeia produtiva brasileira de hortaliças. $13^{\circ}$ Reunião Ordinária da Câmara Setorial da Cadeia Produtiva de Hortaliças/ MAPA; 2017; Brasília, DF.

Ceratti M. Mercado dinâmico: Importantes transformações no perfil e comportamento dos consumidores apontam para a necessidade da agroindústria se manter cada vez mais atenta ao atendimento de novas demandas. Rev Cultivar Hortal Frutas. 2018 Abril;109.

2. Nascimento WM, Lima LB. Condicionamento osmótico de sementes de berinjela visando a germinação sob temperaturas baixas. Rev Bras Sementes. 2008 Abril;30(2):224-227, doi: 10.1590/S010131222008000200029.

3. Rodo AB, Perleberg CS, Torres SB, Gentil DFO, Neto JT. Qualidade fisiológica e tamanho de sementes de cenoura. Sci Agric. 2001 Jan./Mar.;58(1):201-204, doi: 10.1590/S0103-90162001000100031.

4. Luz JMQ, Bittar CA, De Oliveira RC, Nascimento AR, Nogueira APO. Desempenho e divergência genética de genótipos de tomate para processamento industrial. Hortic Bras. 2016;34(4), doi: 10.1590/hb.v34i4.723.

5. Souza JR, Rebouças TNH, Luz JMQ, Amaral CLF, Figueiredo RM, Santana CMP. Potencialidade de fungicidas biológicos no controle de requeima do tomateiro. Hortic Bras. 2014 Jan./Mar.;32(1):115119.

6. Bufalo J, Amaro ACE, Araújo HS, Corsato JM, Ono EO, Ferreira G, Rodrigues, JD. Períodos de estratificação na germinação de sementes de alface (Lactuca sativa L.) sob diferentes condições de luz e temperatura. Semina: Ciênc Agrár. 2012 Maio/Jun.;33(3):931-940, doi: 10.5433/1679$0359.2012 v 33 n 3 p 931$.

7. Deng Z, Song S. Sodium nitroprusside, ferricyanide, nitrite and nitrate decrease the thermo-dormancy of lettuce seed germination in a nitric oxide-dependent manner in light. S Afr J Bot. 2012 June;78:139146, doi: 10.1016/j.sajb.2011.06.009.

8. Vieira EL, Castro PRC. Ação de bioestimulante na germinação de sementes, vigor de plântulas, crescimento radicular e produtividade de soja. Rev Bras Sementes. 2001;3(2):222-228, doi: 10.17801/0101-3122/rbs.v23n2p222-228.

9. De Sousa SM, De Oliveira CA, Gomes EA, Lana UDP, Santos NG, Oliveira LB, Batista FDC. Avaliação de plântulas de milho em solução nutritiva sob a ação de bioestimulantes à base de microrganismos. Anais do Congresso Nacional de Milho e Sorgo 2016, Bento Gonçalves.

10. Burdman S, Okon Y, Jurkevitch E. Surface characteristics of Azospirillum brasilense in relation to cell aggregation and attachment to plant roots. Crit Rev microbial. 2000;26(2):91-110, doi: 10.1080/10408410091154200.

11. Marin VA, Baldani VLD, Teixeira KDS, Baldani JI. Fixação Biológica de nitrogênio: Bactérias Fixadoras de Nitrogênio de Importância para a Agricultura Tropical. EMBRAPA- CNPAB, 1999, 32p. 
12. Batista NS. Diversificação de cultivos de hortaliças associadas ao uso de insumos para fertilidade do solo, em sistema orgânico de produção [dissertação]. Seropédica (RJ): Universidade Federal Rural do Rio de Janeiro, Instituto de Agronomia; 2016. 68 p.

13. Hungria M, De Andrades SD, Prombanza A, Guttierrez FJM, Megrias M. Isolation and characterization of neweficient and competitive bean (Phaseolus vulgaris L.) rhizobia from Brazil. Soil Biol Biochem. 2000;32(11-12):1515-1528, doi: 10.1016/S0038-0717(00)00063-8.

14. Lima ODR, De Oliveira LJMG, Silva MSBSS, Rodrigues AAC. Ação antifúngica in vitro de isolados de Bacillus sp. sobre Fusarium oxysporum f. sp. lycopersici. Rev Caatinga. 2014;27(4):57-64.

15. Bernardi MF. Promotores de crescimento na produção de mudas de alface com e sem fertirrigação [monografia]. Cerro Largo (RS): Universidade Federal da Fronteira Sul, 2017. 39 p.

16. Braga JG. Eficiência de Bacillus subtilis no biocontrole de fitopatógenos e promotor de crescimento vegetal [dissertação]. Gurupi (TO): Universidade Federal do Tocantins, 2015. 87 p.

17. De Araújo F, Marchesi G. Uso de Bacillus subtilis no controle da meloidoginose e na promoção de crescimento do tomateiro. Ciênc Rural. 2009;39(5):1558-1561.

18. Aias CO, Martins I, Da Silva JBT, Silva JP, De Mello SCM. Ação antagônica e de metabólitos bioativos de Trichoderma spp. contra os patógenos Sclerotium rolfsii e Verticillium dahliae. Summa Phytopathol. 2014 March;40(1):34-41, doi: 10.1590/S0100-54052014000100005.

19. Nakagawa, J. Testes de vigor baseados na avaliação de plântulas. In Krzyzanowski, FC, Vieira RD, França NTJB. Vigor de sementes. Londrina: ABRATES,1999. Capítulo Vigor de Sementes: conceitos e testes, p. 2-21.

20. Ferreira DF. SISVAR: um programa para análises e ensino de estatística. Rev Symposium. 2008; 6:3641.

21. Machado DFM, Parzianello FR, Silva ACF, Antoniolli ZI. Trichoderma no Brasil: O fungo e o bioagente. Rev Ciênc Agrár. 2012 Jan/jun;35(26):274-288.

22. Baugh CL, Escobar B. The genus Bacillus and genus Trichoderma for agricultural bio-augmentation. Rice Farm Magazine. 2007;1(4):1-4.

23. Pedroso DC, Muniz MFB, De Tunes LM, Muller J, Junges E, Dutra CB. Qualidade de sementes de cenoura armazenadas após recobrimento com fungicida, pó biológico e polímero. Biosci J. 2014 Oct.;30(2):746-756.

24. Dognini AC. Interferências das aplicações de Trichoderma spp. e Bacillus spp. na qualidade das sementes de cenoura [dissertação]. Piracicaba (SP): Universidade de São Paulo Escola Superior de Agricultura "Luiz de Queiroz"; 2017. 94 p. doi: 10.11606/D.11.2017.tde-19102017-105020.

25. Fukamil J, Cerezini P, Hungria M. Azospirillum: benefits that go far beyond biological nitrogen fixation. AMB Express. 2018;8(73), doi: 10.1186/s13568-018-0608-1.

26. Agrofit. Sistema de Agrotóxicos Fitossanitários. Disponível em: http://agrofit.agricultura.gov.br/agrofit_cons/principal_agrofit_cons. Acesso em: 04 de outubro de 2019.

27. Ethur LZ, Blume E, Muniz MFB, Menezes JP. Trichoderma harzianum no desenvolvimento e na proteção de mudas contra a fusariose do tomateiro. Ciência e Natura. 2008;30(2):57-69, doi: $10.5902 / 2179460 X 9837$.

28. Hashem A, Tabassum B, Alaah EFA. Bacillus subtilis: A plant-growth promoting rhizobacterium that also impacts biotic stress. Saudi J Biol Sci. 2019 26:1291-1297, doi: 10.1016/j.sjbs.2019.05.004.

29. Junges L, Bastos BO, Toebe M, Mullher J, Pedroso DC, Muniz MFB. Restrição hídrica e peliculização na microbiolização de sementes de milho com Trichoderma spp. Comunicata Sci. 2014;5(1):18-25, doi: 10.14295/cs.v5i1.386.

30. Cotrim MF, Alvarez RCF, Seron ACC. Qualidade fisiológica de sementes de trigo em resposta a aplicação de Azospirillum brasilense e ácido húmico. Braz J Biosyst Eng. 2016;10(4):349-357, doi: 10.18011/bioeng2016v10n4p349-357

31. Diniz KA, Oliveira JA, Guimarães RM, De Carvalho MM, Machado JC. Incorporação de microrganismos, aminoácidos, micronutrientes e reguladores de crescimento em sementes de alface pela técnica de peliculização. Rev Bras Sementes. 2006 Jun.;28(3):37-43.

32. Vasconcelos ACP, Siqueira TP, Lana RMQ, Faria MV, Nunes AA, Lana AMQ. Seed iniculation with Azospirillum brasiliense and N-fertilization of corn in the Cerrado biome. Rev Ceres. 2016;63(5):732740, doi:10.1590/0034-737x201663050019. 